\title{
Photoactive titania nanostructured thin films: Synthesis and characteristics of ordered helical nanocoil array
}

\author{
Siglinda Perathoner ${ }^{\mathrm{a},{ }^{*}}$, Rosalba Passalacqua ${ }^{\mathrm{a}}$, Gabriele Centi ${ }^{\mathrm{a}}$, \\ Dangsheng. Su ${ }^{\text {b }}$, Gisela Weinberg ${ }^{\text {b }}$ \\ a Department of Industrial Chemistry and Engineering of Materials and ELCASS, University of Messina, \\ UdR INSTM, Salita Sperone 31, 98166 Messina, Italy \\ ${ }^{\mathrm{b}}$ Department of Inorganic Chemistry and ELCASS, Fritz Haber Institute of the Max Planck Society, \\ Faradayweg 4-6, D-14195 Berlin, Germany \\ * Corresponding author. Tel.: +39 090 6765609; fax: +39 090 391518., E-mail address:perathon@unime.it
}

Keywords: Titania; Nanocoil; Nanotube array; Thin film; Nanostructure

\section{Abstract}

Titania nanostructured thin films have been prepared by anodization of titanium foils at different voltages in the 10-20 V range. They have been characterized by field emission scanning electron microscopy (FESEM), glancing angle X-ray diffraction (GAXRD), UV-vis diffuse reflectance and current-time transients during the anodization process. The observed nanostructure differs from that reported for titania nanotubes (hollow columns) and can be described as helical nanocoils which form an ordered array over the entire surface. The model of formation of these nanostructures (TNT) has been also proposed. The voltage applied during the anodization influences the mean dimension of these TNT, their wall thickness and also their degree of packing. A linear relationship between the wall thickness, in the 5-10 $\mathrm{nm}$ range, and the band gap is observed. The behavior of these samples in the photo-generation of current by irradiation with a low-power lamp simulating solar spectrum has been also studied. A main factor which determine with photo-behavior is the band gap which in turn depends on the characteristics of the TNT. Increasing the voltage during anodization increases the wall thickness and the band gap shifts toward visible region with an improvement of the photo-generated current density. It is also demonstrated that the formation of these helical nanocoils improve the photo-generated current with respect to the sample samples after short anodization where only a titania layer is formed.

Introduction

Titania $\left(\mathrm{TiO}_{2}\right)$ is a well known photo-catalyst with applications ranging from water purification to health protection (indoor and outdoor air purification), $\mathrm{H} 2$ production (by water photodissociation) and preparation of advanced materials (selfcleaning glasses and tissues, etc.) $[1,2]$. The main advantages are related to its ability to withstand photo-corrosion, the low toxicity and cost, and the good quantumyield.On the other hand, current limits of titania as photo-catalyst are related to the band gap in the UV region (3.2 eV for anatase), the low activity with high concentrations of pollutants which may quench surface photo-induced chemistry, and the high rate of recombination of the photo-generated electrons and holes $[3,4]$.

To overcome these problems, together with an intense research activity in modifying the band gap of titania by doping with transition metals $(\mathrm{Cr}, \mathrm{V}$, etc.) or non-metals $(\mathrm{S}, \mathrm{N}, \mathrm{C}, \mathrm{B})$ [5-7], formation of heterojunctions with metal nanoparticles such as $\mathrm{Au}$ [8], and modified systems such as coupled semiconductor $\left(\mathrm{CdS} / \mathrm{TiO}_{2}, \mathrm{CdSe} / \mathrm{TiO}_{2}, \mathrm{SnO} 2 / \mathrm{TiO}_{2}, \mathrm{ZnO} / \mathrm{TiO}_{2}, \mathrm{ZnO} / \mathrm{CdS}\right)$ [9] or composite system such as $\mathrm{WO}_{3} / \mathrm{SiC}-\mathrm{TiO}_{2}[10]$, a significant activity was recently centred on the development of titania oxide thin films having an ordered microstructure [11]. 
In fact, a three-dimensional network of interconnected 15- $20 \mathrm{~nm}$ titania nanoparticles identified so far as the most suitable oxide material architecture for photochemical processes [12] allows an efficient light harvesting and separation of electron- hole pairs [13], but it is limited by the poor electron transport through the network and the high recombination rates at the grain boundaries [14]. Consequently, there is a significant interest in developing ordered nanostructures which could improve these properties and allow at the same time a high accessibility to all the surface area by pollutants. In addition, it is expected that such type of ordered nanostructure could also induce a vectorial-type charge separation which decrease the recombination probability [15] and also may allows a stabilization of oxygen-deficient titania which enhances the visible-light photoactivity $[6,7]$.

Nanostructured titania thin films having a columnar-type growth [15,16], a nanowire [17], nanorods [18] or helical ribbon [19] microstructure, or formed by an ordered array of tapered, conical-shaped nanotubes $[20,21]$ have been synthesized. These thin films, with respect to those prepared by conventional techniques such as dip-coating, have been reported to show enhanced properties in terms of charge separation, photocurrent, visible light response and reactivity connected to the peculiar nanostructure characteristics [11,21-25].

Ordered arrays of titania nanotubes appear particularly interesting. Different modalities of preparation of titania nanotubes have been reported, such as hydrothermal treatment with concentred $\mathrm{NaOH}$ solution of titania powder [26], electrochemical deposition on a polymer mold obtained from a porous aluminum oxide [27], using molecular assemblies of surfactant molecules [22,28], electrophoretic deposition on Nesa1 glass (a commercial transparent electroconductive glass) [29], electrospinning [30], and anodic oxidation of titanium foils $[21,24,31,32]$. The latter appear as the most costeffective to produce large ordered arrays of titania nanotubes.

Recently, the very interesting performances of these ordered arrays of titania nanotubes for visible-light water-photoelectrolysis and photoelectrochemistry [33,34], water photocleavage [35], and in dye-sensitized solar cells $[36,37]$ has been reported. The enhanced properties were attributed to the space charge layer within the tube wall [38], nanotube geometry which allows an improved photoabsorption [39], and longer electron lifetime and diffusion length in $\mathrm{TiO}_{2}$ nanotubes with respect to nanoparticles [36]. These characteristics are highly depending on the dimensions and wall thickness of the nanotubes, their crystallinity, and their packing density, because the charge separation and transport, and the grain boundary effect would greatly depend on such factors. However, notwithstanding the fast increasing number of studies on these materials, there are still large uncertain about how to control the characteristics of these titania nanotubes, and the mechanism of their formation.

We will report in this work the results of an investigation on the preparation of photoactive titania nanostructured thin films in the form of an ordered helical nanocoil array and obtained by anodic oxidation of titanium foils. Being similar materials indicated in literature as titania nanotubes (TNT) array we will also use this indication through the paper, even though it will be evidenced that this is not the more correct description of the nanostructure in our samples. The work is focused on the analysis of the influence of the constant voltage applied during anodization process on the characteristics of the nanostructured titania thin films investigated by current-time transient curves, field emission scanning electron microscopy (FESEM), transmission electron microscopy (TEM), glancing angle Xray diffraction (GAXRD) and UVvisible diffuse reflectance. The behavior of the samples in the photo-generation of current upon irradiation with low-power lamps simulating solar spectrum is also analyzed to determine the relationship between nanostructure and photo-behavior. 


\section{Experimental}

TNT films were prepared by anodizing titanium foils (from Alfa Aesar, slabs of $30 \mathrm{~mm}$ x 40 $\mathrm{mm}$ ) of thickness $2.0 \mathrm{~mm}$ and purity $99.5-99.2 \%$, respectively. Ti foils with lower thickness up to $0.025 \mathrm{~mm}$ have been also investigated, but the results reported here refer to only a $2.0 \mathrm{~mm}$ thickness. Prior to any electrochemical treatment the foils were sonicated in distilled water, and then in isopropyl alcohol for $10 \mathrm{~min}$ each. Then they were dried in air.

Electrochemical experiment were carried out at room temperature with magnetic stirring using an Autolab PGSTAT30 potenziostat/galvanostat in a two-electrode set-up applying different anodizing voltages 10,15 and $20 \mathrm{~V}$ for times ranging from 20 to $45 \mathrm{~min}$, typically $45 \mathrm{~min}$. The electrolyte consisted of $0.5 \mathrm{wt} . \% \mathrm{HF}$ in double distilled water and a platinum electrode served as the cathode. The geometry of the cell was optimized to obtain the formation of the TNT film array. The cell was characterized from an electrolyte volume of about $200 \mathrm{ml}$ maintained under continuous stirring, a distance of $5 \mathrm{~cm}$ between the electrode with the anode in the form of a slabs of $30 \mathrm{~mm} \times 40 \mathrm{~mm}$ and the cathode of a Pt wire. The initial voltage $(6 \mathrm{~V})$ was maintained for $1 \mathrm{~s}$ and then a linear ramp of about $1 \mathrm{~V} / \mathrm{min}$ was applied up to the final voltage (in the 10-20 $\mathrm{V}$ range) which was maintained constant. The $\mathrm{pH}$ was 4.0 in all tests and adjusted using $\mathrm{NH}_{4} \mathrm{OH}$ aqueous solution. AA and XRF were used to check the purity of the solutions and analyze the amount of Ti dissolved in solution after anodization.

The samples were cleaned with deionized water at the end of the anodization process. The annealing of the TNTwas made at $450{ }^{\circ} \mathrm{C}$ in air for $3 \mathrm{~h}$ with heating and cooling rates of 2 ${ }^{\circ} \mathrm{C} / \mathrm{min}$. The structural and morphological characterization of the titania thin films was made by scanning electron microscopy Hitachi S4800 with field emission gun (FEG) (FESEM). The oxide layer thicknesses (lengths and shape of the nanotubes) were directly obtained from SEM cross-section images, while the diameter of the nanotubes and their wall thickness was determined from top-view images. The chemical composition of the oxide layers was determined by EDX. The crystallinity and phase composition of the TNT were determined by glancing angle X-ray diffraction using a Philips X'Pert 3710 equipment In fact, thin film samples require the more specialized, glancing angle technique, for structural characterization. This technique decreases the penetration depth of the X-rays and therefore allows for a more selective sampling of the surface. A glancing angle of 18 was used for all measurements and $\mathrm{Cu} \mathrm{Ka}$ as radiation $(\lambda=$ $0.154178 \mathrm{~nm})$. The system conditions were $35 \mathrm{kV}$ and $20 \mathrm{~mA}$. For phase determination were used the JCPDS file No. 21-1272 for anatase phase of $\mathrm{TiO}_{2}\left(2 \mathrm{u}\right.$ main values at $25.3^{\circ}, 36.9^{\circ}$, $37.8^{\circ}$ and $48.1^{\circ}$ which correspond to the crystal planes of (101), (103), (004) and (200), respectively) and JCPDS file No. 21-1276 for the rutile phase of $\mathrm{TiO}_{2}$ (main $2 \theta$ values at 27.4 $4^{\circ}$, $36.16^{\circ}, 39.2^{\circ}, 41.3^{\circ}, 4454.6^{\circ}$ and $57^{\circ}$ corresponding to the crystal planes of (110), (101), (200), (111), (210), (211) and (220), respectively).

UV-visible diffuse reflectance spectra were recorded using a Jasco V570 spectrometer equipped with an integrating sphere for solid samples. The reference was $\mathrm{BaSO}_{4}$ and the spectra were recorded in air.

The photoresponse of the samples under illumination simulating solar spectrum was measured electrochemically in a standard three-electrode configuration using the same potentiostat of anodization process and a saturated $\mathrm{Ag} / \mathrm{AgCl}$ reference electrode. The photoelectrodes were irradiated from a tungsten lamp $(60 \mathrm{~W})$ put at a distance of about $15 \mathrm{~cm}$ from the sample. The counter electrode was platinum, and photocurrent spectra were obtained at $0.1 \mathrm{~V}$ value of positive bias applied between the photoelectrode and the counter electrode. Frontwall (through the electrolyte) illumination mode was employed, and $0.5 \mathrm{M} \mathrm{KOH}$ purged with $\mathrm{N}_{2}$ was the electrolyte. Before the tests all the samples were annealed at $450{ }^{\circ} \mathrm{C}$ in air for $3 \mathrm{~h}$. 


\section{Results}

\subsection{Characteristics and nanostructure of the titania nanotube (TNT) film}

Reported in Fig. 1A is the FESEM top-view image of the TNT produced at a pH of 4 in 0.5 wt. $\%$ $\mathrm{HF}$ by constant voltage anodization process of $15 \mathrm{~V}$. A well ordered array of TNT is formed. The thickness of the layer is about $200-250 \mathrm{~nm}$, while the mean diameter of the TNT is about $45 \mathrm{~nm}$ with a thickness of the walls of about $7 \mathrm{~nm}$. A closer inspection of the TNT (inset B in Fig. 1) reveals that they have not a tapered conicalshape morphology [20,21], but instead the shape of helical nanocoil (see arrows, for example), similar to rolled paper streamers (see inset $\mathrm{C}$ in Fig. 1). The width of these coils is about $10 \mathrm{~nm}$.

While TNT are usually described in literature as regular and straight hollow cylinders [24,31,33] and their mechanism of formation based on this geometry [31], FESEM and TEM images reported in literature also show a more complex nanostructure which resembles that of pillared rings. The thickness of the TNT walls reported in literature is also typically greater than that observed in our samples, e.g. about $15-20 \mathrm{~nm}$ with respect to 5-10 $\mathrm{nm}$ in our case.

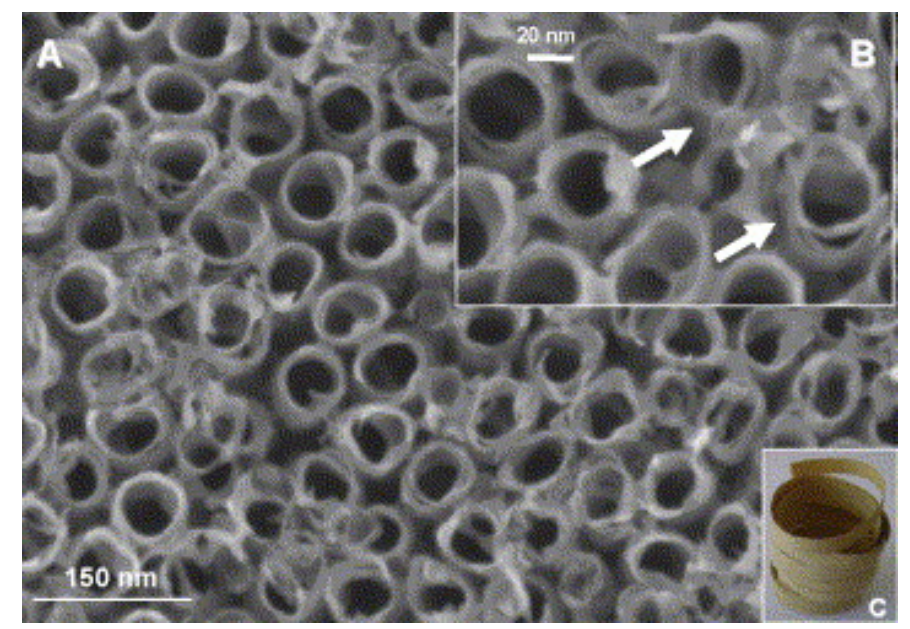

Fig. 1. FESEM image of the sample obtained by anodization at $15 \mathrm{~V}$ for $45 \mathrm{~min}$. In the inset (B), an expansion of some TNT is reported to evidence the nanostructure of helical nanocoil. In the inset (C), a photo of a rolled paper streamer is reported as example to better evidence the nanostructure.

Grimes and co-workers [35] reported that the titania nanotube wall thickness is a key parameter influencing the magnitude of the photoanodic response and the overall efficiency of the watersplitting reaction, and in general that the nano-order of tubular architecture influences the charge separation and transport [40]. Therefore, it may be expected that the different nanostructure we observed in our samples (helical nanocoil) with respect to the cylindrical nanotube structure reported earlier in literature, and the different wall thickness as well, influences the photobehavior.

Another element of interest derives from recent observations by Motojima et al. [41], studying helical $\mathrm{TiO}_{2}$ /carbon microcoil (CMC) composite microtubes and pure helical $\mathrm{TiO}_{2}$ microtubes without a carbon microcoil core. These samples were prepared by adding a $\mathrm{TiO}_{2}$ layer on the surface of CMC templates using a sol-gel or CVD process [42]. Motojima et al. [41] showed that the helical structure enhances the photocatalytic activity of $\mathrm{TiO}_{2}$, and suggested the generation of inductive microelectrical current induced by the irradiation of UV light, resulting in the generation of micromagnetic fields around the tubes. Similarly, it may be suggested that the photo-generated electrons in these helical nanocoils may be transported not along the axial direction of growth of the nanotube, as may be expected for a regular cylindrical nanostructure, but probably following the helical nanocoil path. The photocurrent generated upon irradiation 
would generate inside the TNT a magnetic field which may polarize adsorbing molecules or influence photocatalytic properties. This suggestion requires further investigations to be demonstrated.

It may be also noted that the packing of TNT is not very dense. The degree of packing (e) of the TNT film, e.g.

$$
\varepsilon=\frac{\pi \cdot \alpha \cdot d^{2}}{4 \cdot l^{2}}
$$

where $d$ is the mean external diameter of the TNT, a the number of TNT present in the area considered and 1 is the side of the square of the considered area, is about 0.4. However, the packing is relatively homogeneous in the various parts of the slab used for the anodic process of TNT film growing.

The annealing of the TNT film at $450{ }^{\circ} \mathrm{C}$ does not change significantly the overall morphology of the thin titania film. In Fig. 2A, the top-view FESEM images of the film before (a) and after calcination (b) are compared, while in Fig. 2B, the images at a higher resolution of the same samples are reported. In order to better evidence the effect of the annealing, the micrograph of the TNT film after annealing in Fig. 2B is put as an inset of that before annealing, e.g. directly after the anodization process.

The annealing do not lead to a significant change in the shape, wall thickness, packing density and morphology of the TNT (Fig. 2B), but small irregularly shaped titania appear on the surface (see arrow in Fig. 2A,b) and the presence of TNT may be better evidenced on the whole titanium foil (Fig. 2A).

Glancing angle X-ray diffraction results on the effect of annealing temperature on the phase composition are reported in Fig. 3. In all cases, only titania phase have been detected, apart reflections due to titanium substrate used for growing the TNT and small reflections due to sample holder.

After the anodization process (diffractogram a in Fig. 3), no reflections due to titania could be detected, apart from a broad peak in the 20-30 $2 \theta$ range which may suggest the presence of only amorphous titanium oxide. After annealing at $450{ }^{\circ} \mathrm{C}$ for $3 \mathrm{~h}$ in air, the typical reflections of $\mathrm{TiO}_{2}$ in the anatase form appear, while for an annealing at a slightly higher temperature $\left(500{ }^{\circ} \mathrm{C}, 3 \mathrm{~h}\right)$, the weak reflections for $\mathrm{TiO}_{2}$ rutile start also to be noted.

The appearance of $\mathrm{TiO}_{2}$ anatase reflections only by annealing at $450{ }^{\circ} \mathrm{C}$ and of rutile phase at higher temperature may suggest that the TNT are amorphous after the anodization process and become crystalline after the annealing process, in agreement with literature [32], [33] and [43]. It was also reported by Varghese and co-workers [43] that the anatase crystallites at the tube walls do not undergo transformation to rutile phase, due to constraints imposed by the walls [43], and that the rutile crystallites originate in the oxide layer underneath the nanotube [33], e.g. after annealing, the sample can be viewed as a hollow nano-column made of stacked anatase crystallites with a rutile base.

In contrast with these literature indications, we may note that the relative intensities of the three main reflections of the $\mathrm{TiO}_{2}$ anatase $(101,004,200)$ are in well agreement with those expected for a 3D crystalline particle of $\mathrm{TiO}_{2}$ anatase:

- $\mathrm{TiO}_{2}$ anatase particles (relative intensity and reflection): 100 (101), 20 (004) and 28 (200).

- TNT: 100 (101), 21 (004) and 23 (200). 

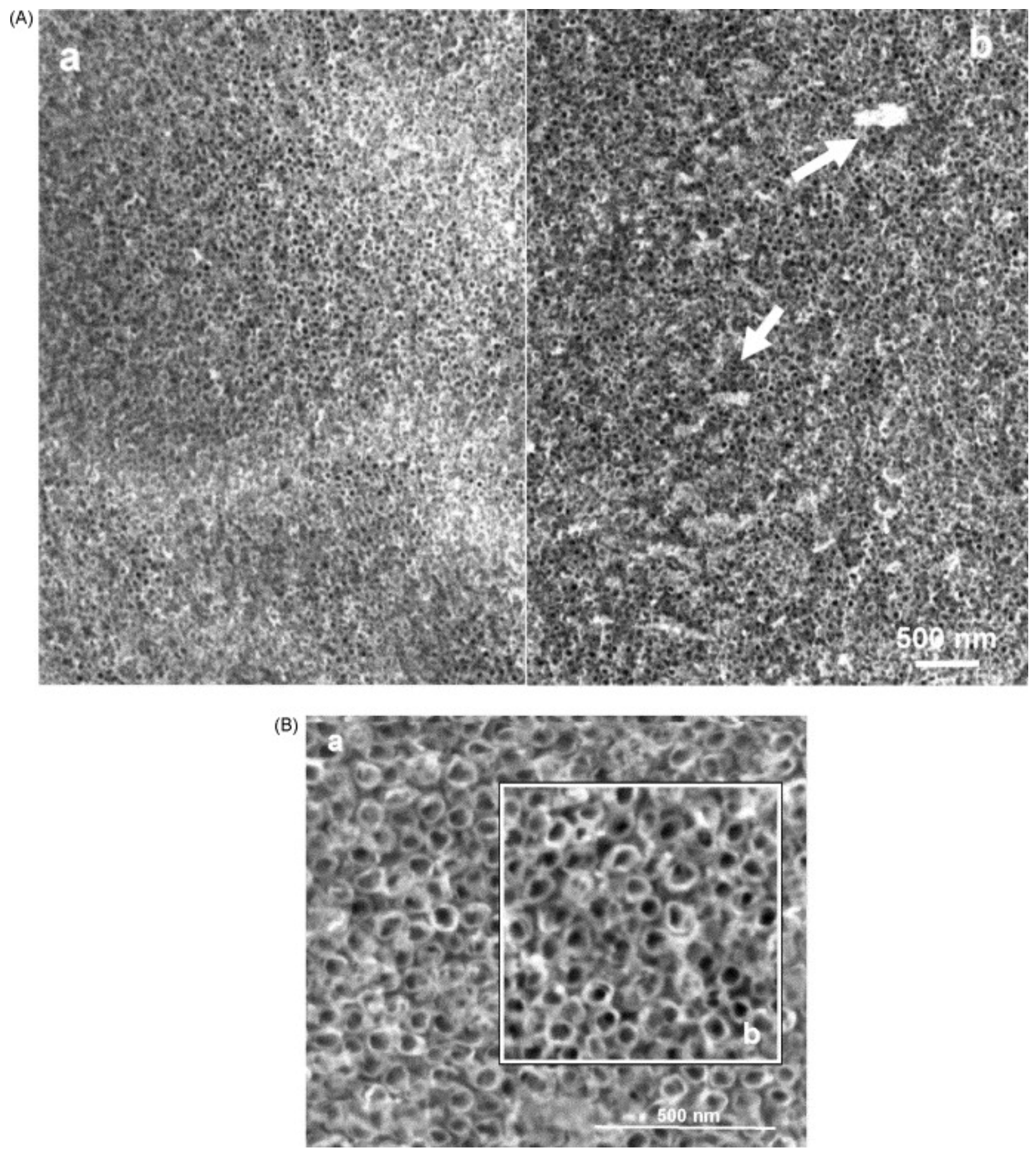

Fig. 2. FESEM of the same sample of Fig. 1, after anodization (a) and after further annealing in air at $450{ }^{\circ} \mathrm{C}$ for $3 \mathrm{~h}$ (b). (A) and (B) are images at different resolution.

Due to the hollowed column shape of the TNT with wall thickness of few nm, the Miller indexes relative to basal plane, e.g. $(00 l)$, should be less intense in particular with respect to those on the perpendicular direction to the basal plane, e.g. $(h 00)$ and $(0 k 0)$. The fact that this is not present in the observed GAXRD reflections of TNT indicates that the observed crystallization process is probably related to only the oxide layer underneath the nanotube and/or the small oxide particles on the top of the TNT film. This does not exclude that TNT are also crystalline, but they give not coherent X-ray reflections to be detected by GAXRD. Later, this concept will be discussed in a more detail. 


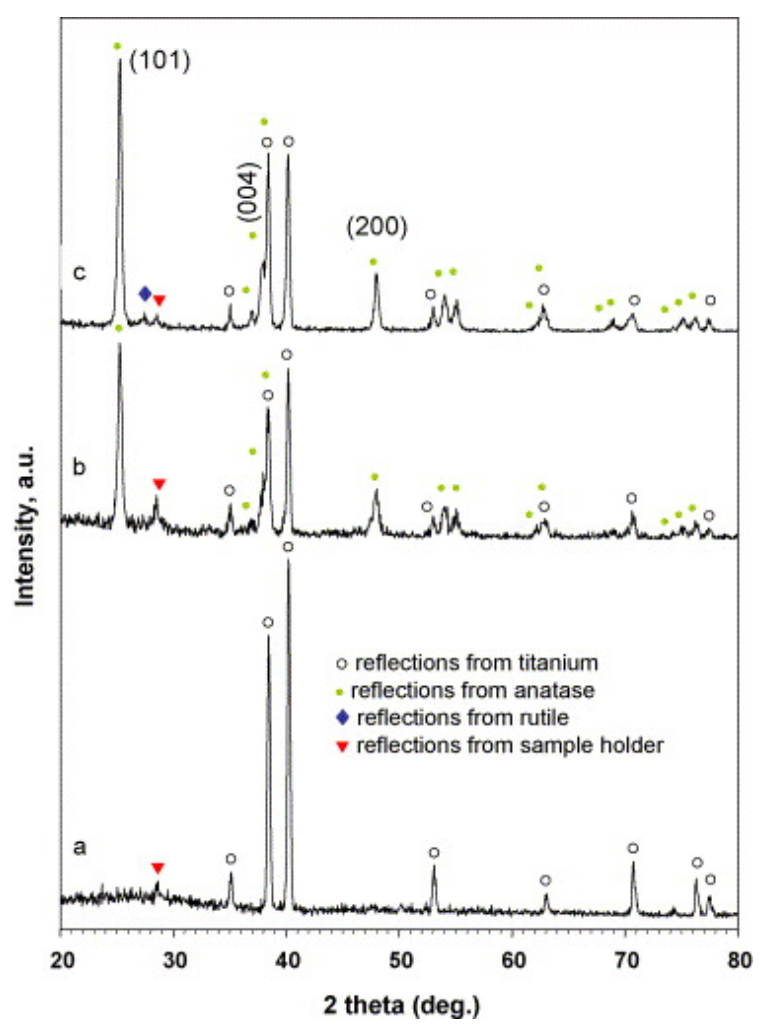

Fig. 3. GAXRD of the same sample of Fig. 1 after anodization (a), further annealing in air at $450{ }^{\circ} \mathrm{C}$ for $3 \mathrm{~h}$ (b) and $500{ }^{\circ} \mathrm{C}$ for $3 \mathrm{~h}(\mathrm{c})$.

FESEM images (Fig. 1) are consistent with the presence of a crystalline sample already after the anodization process, because it was not a significant change in morphology and thickness during the annealing (Fig. 2) as expected when a change from amorphous to crystalline state occurs during this process. This indication was confirmed by TEM images (not reported here) indicating the presence of crystalline $\mathrm{TiO}_{2}$ already after anodization.

Reported in Fig. 4A are the UV-visible diffuse reflectance (UV-vis DR) spectra of TNT film after the anodization process and after further annealing (calcination at $450{ }^{\circ} \mathrm{C}$ for $3 \mathrm{~h}$ ). The samples are the same of those which FESEM images are reported in Fig. 2. For reference the UV-vis DR spectrum of $\mathrm{TiO}_{2}$ P25 (Degussa) is also reported. TNT films before and after annealing show a main transition near $350-400 \mathrm{~nm}$, similar to $\mathrm{TiO}_{2} \mathrm{P} 25$. It should be observed that this reference sample has a band gap shifted to lower frequencies, e.g. towards the visible, with respect to pure $\mathrm{TiO}_{2}$ in the anatase form due to the presence of about $20 \mathrm{wt} . \%$ of rutile phase in the P25 sample.

With respect to P25, the TNT films both before and after annealing at $450{ }^{\circ} \mathrm{C}$ show the presence of a diffuse adsorption in the 400-1200 nm region with the clear presence of interference fringes. After annealing, these interferences fringes become more intense and their frequency decreases.

It is known that interference fringes are produced in thin films and that the amplitude of these fringes is related to film thickness in transmission spectra [44], although for diffuse reflectance spectra the identification of a relationship is more complex [45]. In addition, the presence of voids in the thin film structure (for example, a Si film containing spherical voids) induces light scattering at the voids which modifies and attenuates the fringe pattern [46]. In a porous solid constituted by small irregular nanoparticles, e.g. an XRD amorphous oxide thin film, the noncoherent diffuse light scattering would produce the complete attenuation of the interference fringes in diffuse reflectance spectra. The presence of interference fringes requires the presence 
of a nanostructure having both long- and short-order range. In literature, TNT are typically described as an aggregate of small amorphous $\mathrm{TiO}_{2}$ particles which crystallize only by annealing [43]. However, for such a model of nanostructure, no interference fringes are expected.

Therefore, the observation of clear interference fringes in the UV-vis DR spectra in the TNT film even after the anodization process (Fig. 4A, spectrum 1) suggests the presence of an ordered and crystalline nanostructure, e.g. that the nanotube are already crystalline, notwithstanding the absence of XRD reflections. However, it should be observed that more definitive conclusions require a quantitative analysis of the interferences fringes. This analysis is already quite complex for amorphous thin oxide films and requires complex models. As far as we know, there are no similar studies for ordered arrays of oxide 1D nanostructures.

The band gap region, e.g. the region at wavelength $<400 \mathrm{~nm}$, e.g. gives additional interesting information. The optical band gap of $\mathrm{TiO}_{2} 3 \mathrm{D}$ particles is well known and falls at 3.20 and 3.03 $\mathrm{eV}$ for anatase and rutile particles, respectively. It is also known that in general the band gap shifts to higher energies (shorter wavelengths), e.g. the band gap increases, decreasing the size of $\mathrm{TiO}_{2}$ particles, due to quantum confinement effect. However, the band gap in 2D and 1D titania nanostructures is less known and therefore it is better to summarize literature observation before to analyze our results.
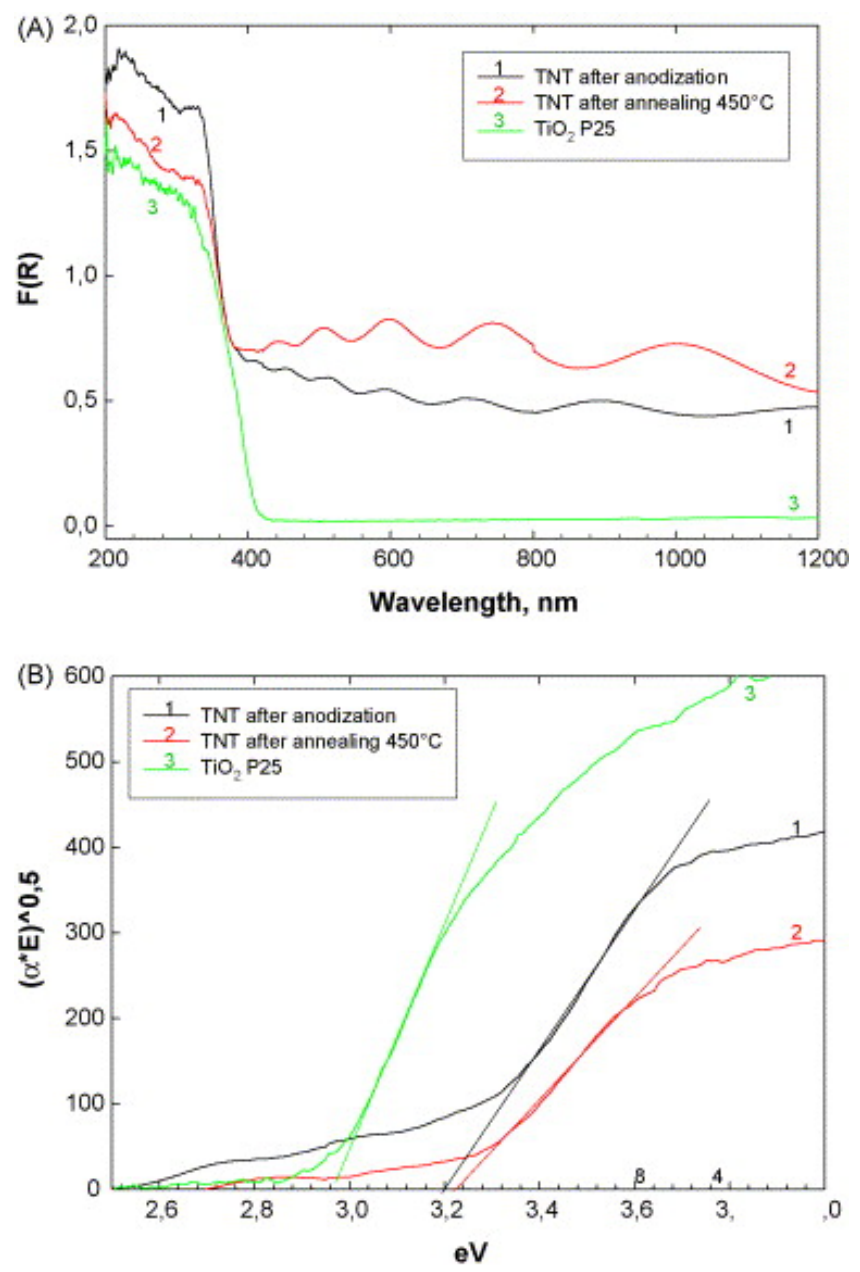

Fig. 4. (A) UV-visible diffuse reflectance spectra of the same sample of Fig. 1 after anodization (a), and further annealing in air at $450{ }^{\circ} \mathrm{C}$ for $3 \mathrm{~h}$. The spectrum of reference Degussa $\mathrm{TiO}_{2} \mathrm{P} 25$ is also reported. (B) Elaboration of the results in ' $\mathrm{A}$ ' to determine the band gap. 
In $\mathrm{TiO}_{2}$ thin films epitaxially deposited by magnetron sputtering, the band gap was reported at $3.37 \mathrm{eV}$ for anatase (on sapphire substrate) and 3.51 for rutile on $\mathrm{SrTiO}_{3}$ [47]. This result is in agreement with the expected increase of the band gap due to a 2D quantum confinement effect. However, the band gap of a single-layer $\mathrm{TiO}_{2}$ sample, with thickness less than $1 \mathrm{~nm}$, was reported to fall at $3.15 \mathrm{eV}$ [48], e.g. a shift to a lower band gap (with respect to anatase $\mathrm{TiO}_{2}$ particles) and thus opposite to what expected based on 2D quantum confinement [49]. Ab initio calculations [47] indicate that for both rutile or anatase the lattice constant $c$ has to be compressed, and lattice constant $a$ has to be expanded, in order to achieve a smaller band gap. Therefore, when the thin film of titania is characterized by an ordered array of 1D nanostructures (nanotubes, etc.), it may be expected that the increase in the band gap expected for thin films is not present. In fact, in aligned rutile and anatase $\mathrm{TiO}_{2}$ nanorods [50], the band gap was observed at 3.0 and $3.2 \mathrm{eV}$, respectively, due to the elongation along the $c$-axis of these nanostructures.

To estimate the band gap in our samples, it may be assumed that the fundamental absorption of the $\mathrm{TiO}_{2}$ crystal possesses an indirect transition. In this case, the band gap of the TNT film samples and of a reference $\mathrm{TiO}_{2} \mathrm{P} 25$ sample can be evaluated by plotting $(\alpha \cdot E)^{1 / 2}$ (where $\alpha$ and $E$ $=h \cdot v$ represent the absorption coefficient and photoenergy, respectively) against $E$ [50] and [51]. As shown in Fig. 4B, the intercepts defining the energy gaps for the $\mathrm{TiO}_{2} \mathrm{P} 25$ is about $3.0 \mathrm{eV}$, in agreement with the presence of about $30 \%$ rutile phase in P25 sample. The band gaps for TNT film before and after annealing at $450{ }^{\circ} \mathrm{C}$ are 3.20 and $3.24 \mathrm{eV}$, respectively (Fig. 4B). This value is in good agreement with that found for crystalline anatase $\mathrm{TiO}_{2}$ nanoroads [50] and singlelayered $\mathrm{TiO}_{2}$ with a thickness less than $1 \mathrm{~nm}$ [48]. This observation confirms that TNT are probably crystalline already after the anodization and in the anatase form. In fact, anatase amorphous $\mathrm{TiO}_{2}$ thin films would give a band gap at about $3.5 \mathrm{eV}$ [52].

\subsection{Effect of the voltage during the anodization}

Reported in Fig. 5 are the FESEM images of the samples obtained after anodization at a constant voltage of $10 \mathrm{~V}$ (top image) and $20 \mathrm{~V}$ (bottom image) and which could be compared with the FESEM image of the sample obtained at $15 \mathrm{~V}$ (Fig. 1). In order to better evidence the change in the dimensions of the TNT and in their packing, an area with dimension $300 \mathrm{~nm} \times 300 \mathrm{~nm}$ is highlighted in Fig. 5. It is evident that both the dimensions of the TNT, their wall thickness and their degree of packing are influenced by the voltage during anodization. Fig. 6 summarizes the dependence of the TNT inner diameter and of the degree of packing from this parameter. In Fig. 6 , the error bar indicates the wall thickness which increases on increasing the voltage during anodization.

However, it may be also observed that the nanostructure of the TNT is the same of that discussed regarding Fig. 1, e.g. a helical nanocoil as can be clearly evidenced in the sample prepared at 20 $\mathrm{V}$, for example. Therefore, the voltage during the anodization changes the dimensions and wall thickness of the TNT and their packing as well, but do not changes their mechanism of formation.

Reported in Fig. 7A are the UV-vis DR spectra of the samples obtained at different voltage during anodization. In all samples, the interference fringes in the region above $400 \mathrm{~nm}$ could be evidenced. The frequency of these oscillations, e.g. the number of oscillations each $100 \mathrm{~nm}$ of wavelength in the spectral region from 500 to $1200 \mathrm{~nm}$, depends on the mean diameter of the TNT. In the inset of Fig. 7A, it is shown that a linear relationship could be observed between TNT inner diameter and the frequency of these interferences fringes. This indicates that this is the main parameter determining these interferences fringes in these samples, while the film thickness is similar. 

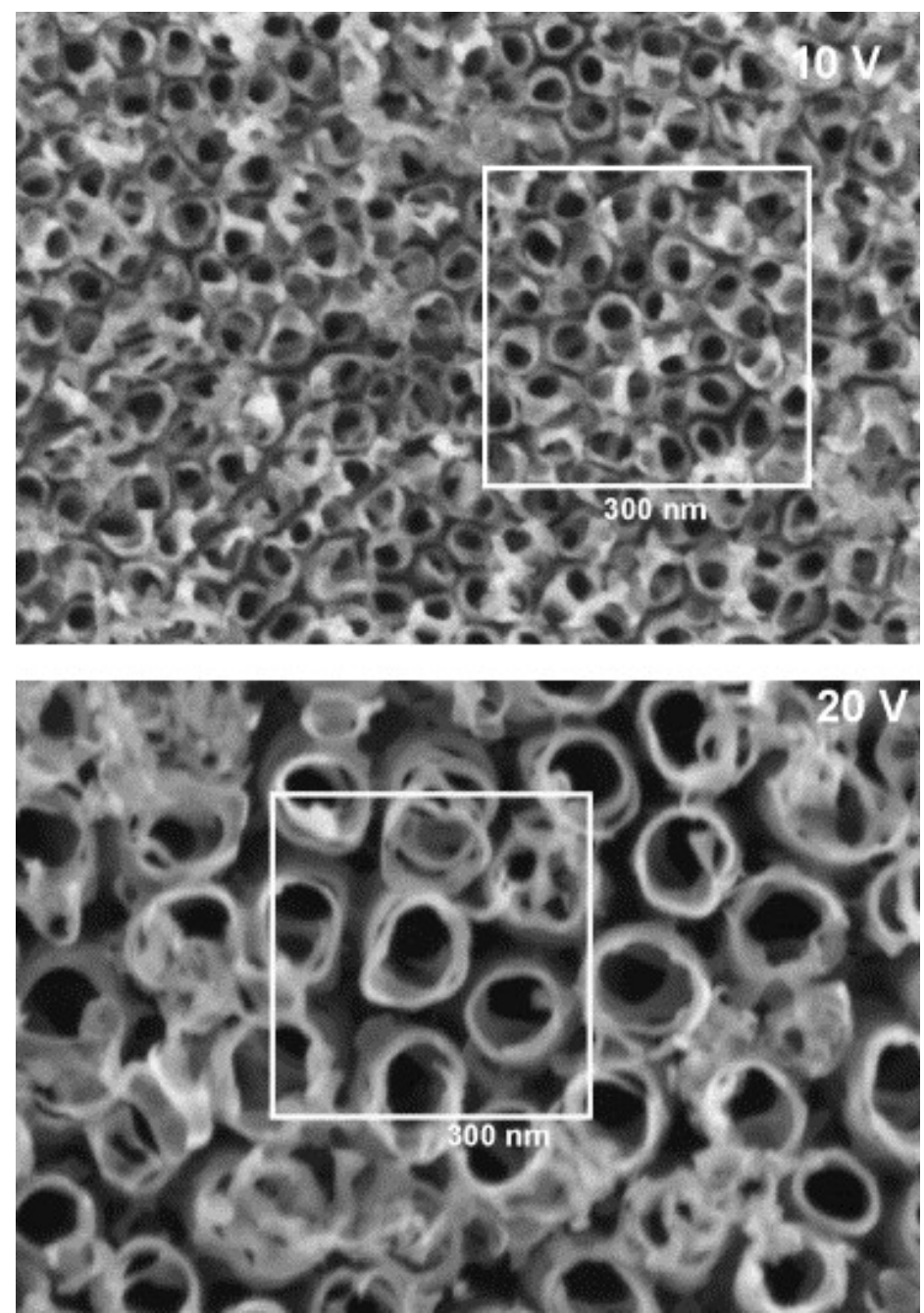

Fig. 5. FESEM images of the samples obtained by anodization at $10 \mathrm{~V}$ (top image) and $20 \mathrm{~V}$ (bottom image) for 45 $\min$.

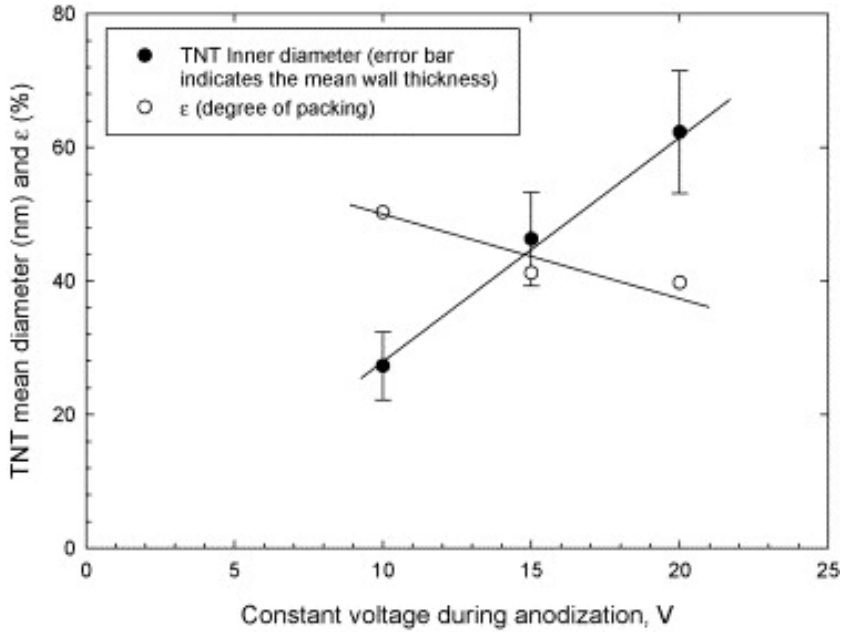

Fig. 6. Relationship observed between voltage applied during anodization and TNT mean diameter and degree of packing of the TNT film. The error bar on the value of TNT mean diameter indicates the mean wall thickness of the TNT. 

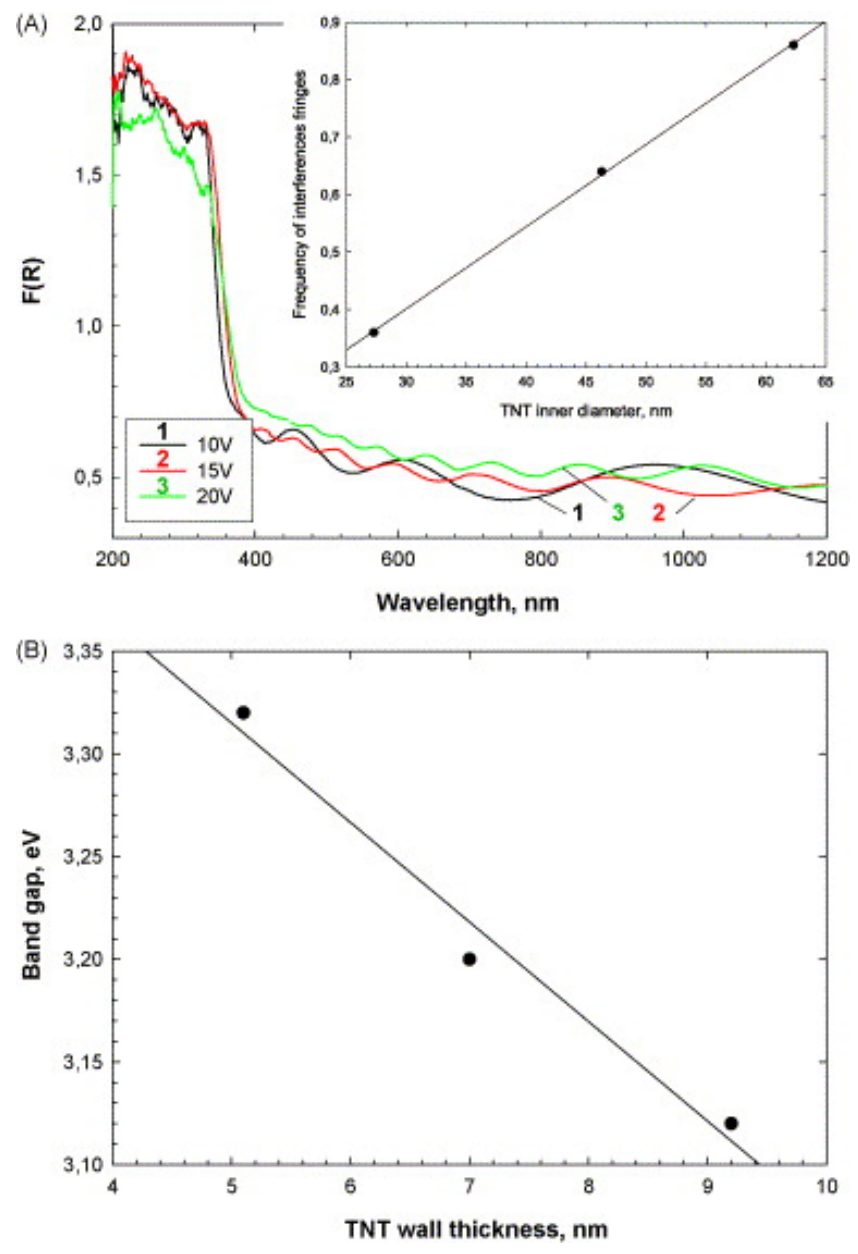

Fig. 7. (A) UV-visible diffuse reflectance spectra of TNT films obtained at different anodization voltage for $45 \mathrm{~min}$. In the inset, the relationship between frequency of the interferences fringes (see text) and TNT inner diameter is reported. (B) Relationship between band gap determined from spectra reported in 'A' and TNT wall thickness.

The voltage during the anodization influences also the band gap. Reported in Fig. 7B is the observed relationship between band gap, estimated with the procedure discussed above, and the TNT wall thickness. The linear relationship indicates that the thickness of the walls of the TNT determine the band gap. The band gap is shifted to lower frequencies with respect to that observed in $\mathrm{TiO}_{2}$ anatase nanoparticles [49] and also with respect to that observed for $\mathrm{TiO}_{2}$ anatase small particles in the walls of mesoporous SBA-15 [53].

Reported in Fig. 8A are the current versus time transients determined during the anodization process. Fig. 8B shows an expansion of the region during the first 2-3 min. The current transient can be explained on the basis of the analogy with the formation of porous aluminum oxide by anodization [54], [55] and [56]. There is a fast initial decrease of the current due to the formation of the oxide barrier layer which decreases the electric field strength. This decrease is exponential, because the ionic current density depends exponentially on the latter parameter. Within about a minute, the net current reaches a minimum (point $\mathrm{A}$ ). The net current, $J$, is a combination of the current due to the barrier layer, $J_{\mathrm{B}}$ and the current due to the pore formation, $J_{\mathrm{P}}$ (see inset in Fig. 8A). In the first few seconds, the current due to the formation of barrier layer dominates and hence the rapid decrease in the net current is observed. Then the current due to the pore formation is more prominent and hence the net current increases and reaches a steady state value. When the steady state is reached the pore structure is stabilized. The increase in the 
net current after point $\mathrm{A}$ is due to the acid dissolution of $\mathrm{Al}_{2} \mathrm{O}_{3}$ barrier with formation of the pores.
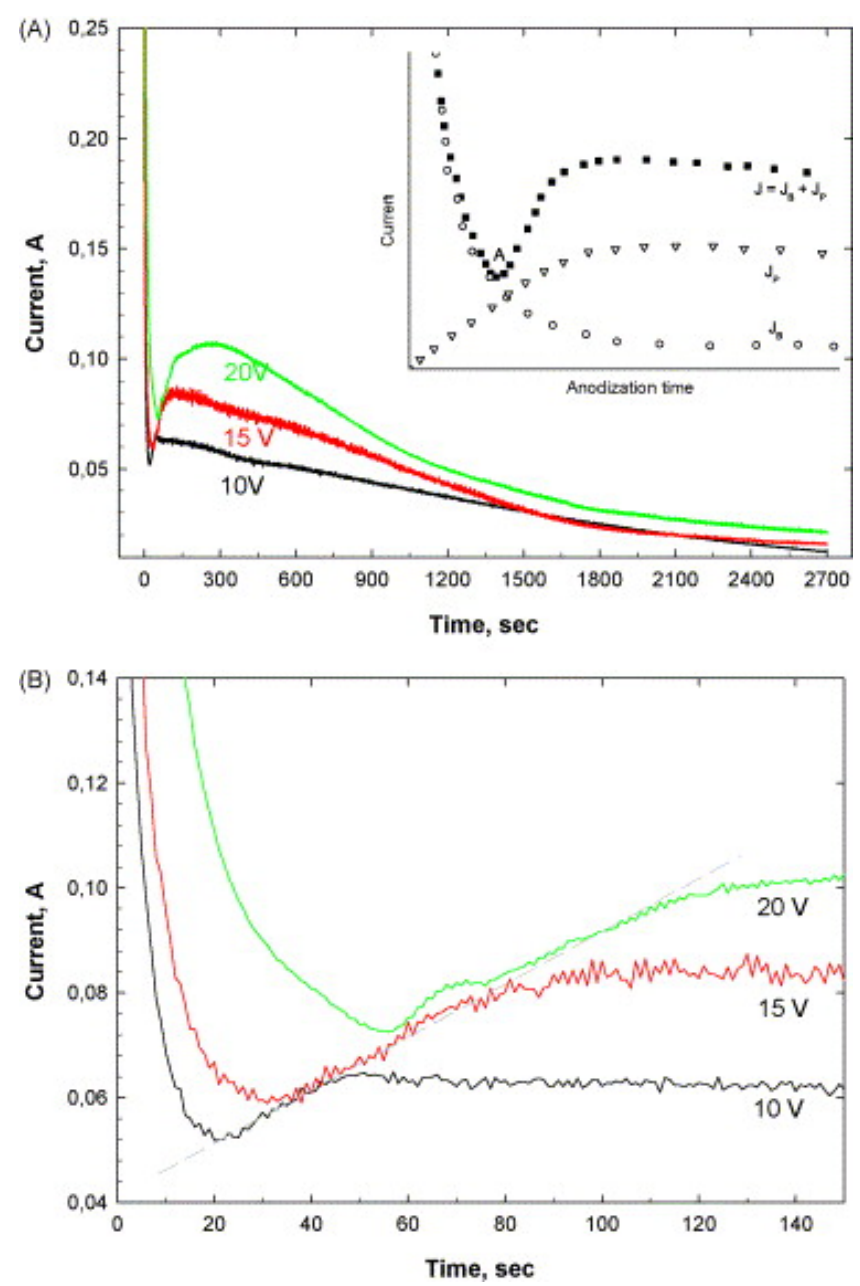

Fig. 8. (A) Current-time transient curves observed during anodization at different voltages. In the inset, the deconvolution of the general curve in two components is shown. (B) Expansion of the current-time transient curves during the first part of anodization.

The mechanism of formation of these pores can be briefly summarized as follows. During the first part of anodization process, a hexagonal cell array of oxide particles forms. The pores initiate in the centres of these hexagonal cells, and the pore growth is due to the field assisted hydrogen ion attack on the oxide layer. Aluminum ions migrate from the metal across the metal/oxide boundary into the barrier oxide and the oxygen ions formed from water at the oxide/electrolyte interface migrate into barrier layer. This migration of ions occurs because of the large potential drop across the barrier layer at the pore bottoms, due to which the barrier layer acts as a dielectric. This leads to the dissolution of oxidized aluminum during anodization and the pores are hence formed. The ion migration and oxide dissolution at the pore bottom depend strongly on the applied potential. Self-organization of the pores has been attributed to the repulsive interaction between the pores during their growth.

As discussed later, this mechanism of formation does not apply correctly to the case of formation of TNT film, but the general features for the interpretation of the current versus time transients during the anodization process are valid. In Fig. 8B, reporting an expansion of the initial stage during the anodization, it is possible to see that the rate of the process of formation of the TNT, e.g. the curve $J_{\mathrm{P}}$ in the inset of Fig. $8 \mathrm{~A}$, do not depend on the voltage of anodization. In fact, the rate of this increasing part of the current transient for the three curves obtained at different 
anodization voltage is the same (see dotted line). However, the value of the current which can be obtained after about 3 min depends on the voltage during anodization (see Fig. 8B). This means that the local electric field during the process of anodization is different. Fig. 9 shows that the value of the current obtained after $150 \mathrm{~s}$ can be put in a linear relationship with the TNT wall thickness. This indicates that this parameter and the mean inner diameter of the TNT as well, depend on the local electric field during the anodization process.

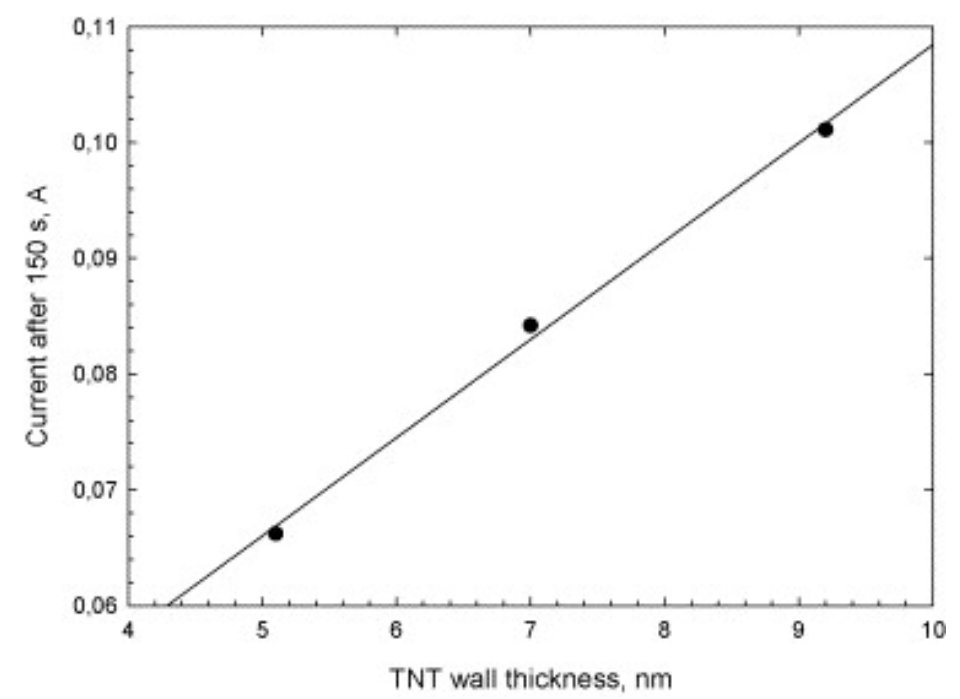

Fig. 9. Relationship observed between current after $150 \mathrm{~s}$ in Fig. 8 and TNT wall thickness.

3.3. Photocurrent generation by TNT under irradiation with low power lamp simulating the solar spectrum

Reported in Fig. 10 is the behavior of TNT samples prepared at $15 \mathrm{~V}$ of anodization potential, but different times of anodization $(0,20$ and $40 \mathrm{~s}$, and $45 \mathrm{~min}$, see Fig. 8), in the photo-generated current transients upon exposure to a low power lamp (about $0.1 \mathrm{~W} / \mathrm{cm}^{2}$ ) simulating the solar spectrum, e.g. having about $4 \%$ of the flux in the UV-A domain. The background dark current has been subtracted. Samples have been annealed at $450{ }^{\circ} \mathrm{C}$, because the intensity of photogenerated current is about twice after this treatment.

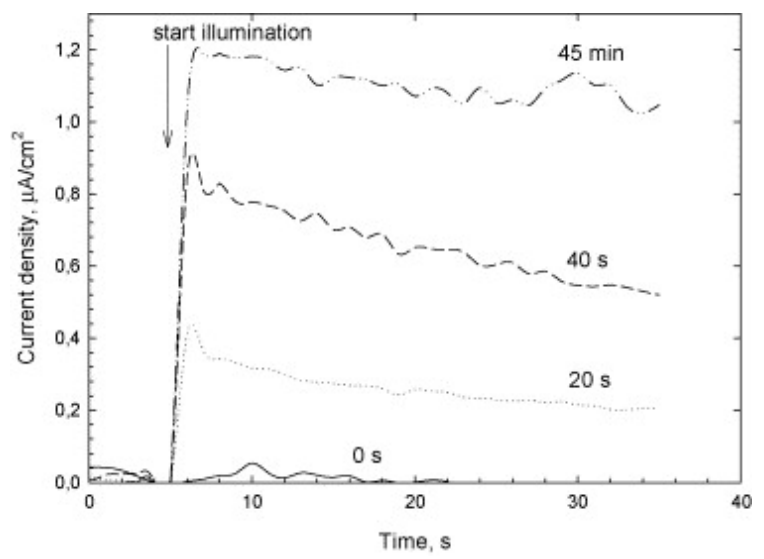

Fig. 10. Photo-generated current density after irradiation with a low-power lamp with visible spectrum. The time indicated in the different curves is the time of the anodization process at $15 \mathrm{~V}$.

Under irradiation, there is a fast increase in the photo-generated current which then slowly decrease reaching a stationary behavior after about 1-2 min of irradiation. No photo-generation of current is observed in the sample which has not anodized, while after $20 \mathrm{~s}$ of anodization a 
photo-generated current may be observed. The intensity of the photo-generated current after $40 \mathrm{~s}$, e.g. in correspondence of the minimum in the current transient (Fig. 8B) which corresponds to the maximum thickness in the titania oxide barrier formation, is about twice that after $20 \mathrm{~s}$. However, a further increase is observed when the TNT are fully developed, e.g. after 45 min.

Reported in Fig. 11A is the photo-generated current density (after $30 \mathrm{~s}$ of irradiation) as a function of the time of anodization and the voltage applied during anodization. The same trend discussed above regarding the time of anodization on the current photo-generation can be observed in the three samples. The photo-generated current density increases with the voltage during anodization. This could be put in relation to the increase of the TNT inner diameter and/or the increase in the wall thickness or better to the shift towards the visible region of the band gap of TNT associated to the increase of wall thickness (Fig. 11B). The relationship is not very good indicating that the band gap is not the only factor determining the performances of TNT in photo-generation of current under irradiation with a low power lamp simulating solar spectrum. In fact, the change in the anodization voltage modifies also the degree of packing of TNT and their mean diameter (Fig. 6). Therefore, the effectiveness of irradiation, e.g. the area effectively irradiated, would also change.
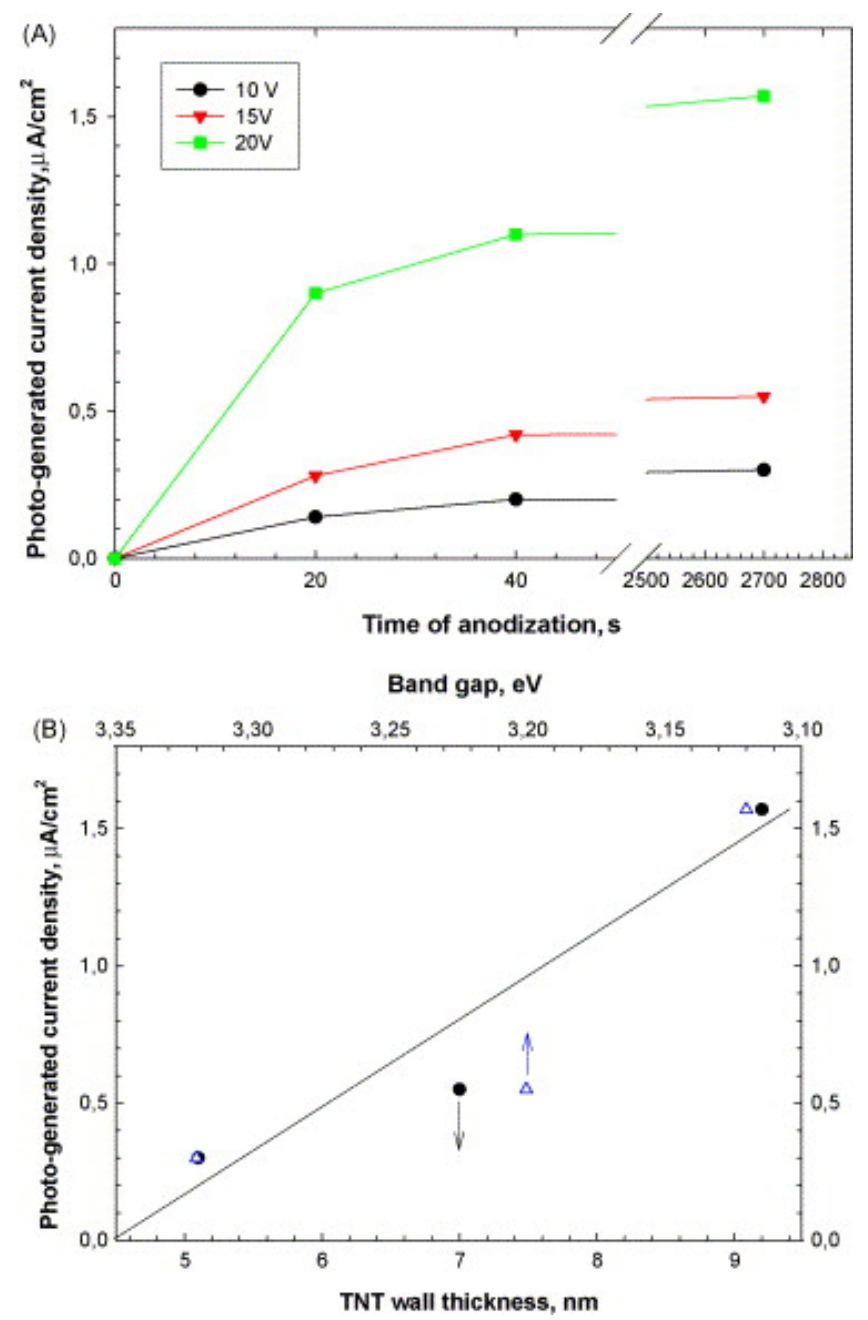

Fig. 11. (A) Dependence of the photo-generated current density (after $30 \mathrm{~s}$ ) and the time of anodization for samples prepared at different voltage. (B) Relationship observed between current density and TNT wall thickness and between current density and band gap. The arrows indicate the two different axes (bottom and top) to which the two series of points refer. 
In addition, Figs. 4A and 7A suggest that probably the main absorption edge near $350-400 \mathrm{~nm}$ show also a long tail extending over the visible region. This tail is covered from the interference fringes due to thin film and therefore clear conclusions cannot be derived. However, probably the long tail is due to the presence of oxygen vacancies stabilized by the nanostructure or induced from the introduction of small amounts of $\mathrm{N}$ in the titania nanostructure (the anodization is made in the presence of $\mathrm{NH}_{4} \mathrm{OH}$ to buffer the $\mathrm{pH}$ at 4.0), similarly to what observed for $\mathrm{N}$ - or C-doped $\mathrm{TiO}_{2}$. Nevertheless, the relationship shown in Fig. $11 \mathrm{~B}$ indicates that the band gap, which in turn depends on the TNT characteristics, is one of the main factors determining the photo-activity.

\section{Discussion}

TNT films which has been studied in this work show a wall thickness about one-half or less than that usually reported in literature, due to a different cell geometry and reaction conditions. The smaller wall thickness, although not beneficial for the photo-behavior, as shown in Fig. 11B, allows to better evidence the nanostructure of the TNT which is different from what indicated in literature of hollow columns. Fig. 1 shows that the structure of TNT, at least in the conditions of synthesis we used, is characterized by the presence of helical nanocoils which form an ordered array over the entire surface of titanium foils used for the anodization. The voltage applied during the anodization influences the mean dimension of these TNT, their wall thickness and also their degree of packing as shown in Fig. 6. All these characteristics are relevant in determining the properties of these materials, and their use as photo-catalysts, but more in general also as catalyst and or catalytic support for other reactions.

The mechanism of formation of these TNT has been often adapted in literature from that described for the formation of porous alumina by anodization [54], [55] and [56]. Also in the case of anodization of aluminum foil an ordered array of pores forms, but these can be described as an ordered array of holes which form on the aluminum oxide surface produced during the anodization process. Figs. 1 and 5 instead evidence that in the case of titanium the TNT growth from the bottom surface, in agreement with literature, and also that they are physically separated each other. FESEM cross-section images of the TNT, not reported here for sake of conciseness being similar to those already published by other research groups working on the anodization of Ti foils, further demonstrate that the TNT growth from the bottom surface.

The mechanism of formation of TNT described by Varghese and co-workers [43] is essentially based on a nucleation and growth model derived from aluminum anodization. In the latter the porous structures during the anodization forms through two processes: field-enhanced oxidation of aluminum and field-enhanced oxide dissolution [54], [55] and [56]. Inside the pore channel there are two interfaces: solution/oxide and oxide/metal. Field-enhanced oxidation occurs at the metal/oxide interface near the pore bottom when the oxygen containing ions $\left(\mathrm{O}_{2}{ }^{-} / \mathrm{OH}^{\urcorner}\right)$transport from solution to the oxide layer, along the direction of the pore growth. At the same time, metal ions $\left(\mathrm{Al}^{3+}\right)$ migrate from metal to the solution/oxide interface and dissolve into the solution. Since the electric field can enhance the migration of the metal ion, the later process is called field-enhanced dissolution. As the electrical field intensity at the pore bottom is much higher than that at the wall, aluminum will be consumed at a high rate near the bottom of the pore, allowing continuous growth of the pore depth. The differences in the case of titanium are indicates to release only to an etching rate of the oxide in solution comparable with that of the field-enhanced dissolution [19].

Zhao et al. [32] observed that HRTEM images at different parts of TNT (bottom, middle, top) indicate a single crystal structure, which does not agree with above model in which the TNT forms by aggregation of small amorphous particles. The model proposed by Zhao et al. [32] is of crystallographic orientations via oriented attachment. These models agree with our data which, however, indicate that the growth do not occurs along the axial direction of the TNT, but in the 
form of a nanocoil which growth helicoidally. We may suggest that probably this type of growth is induced from the electrical field at the bottom of the TNT, but should be remarked that further more specific studies are necessary to clarify the mechanism of growing of nanocoils. Due to the continuous process of field-enhanced oxidation of titanium and field-enhanced oxide dissolution probably the electrical field is not perpendicular to the surface, but slightly rotates around the axial axis of TNT growth. This description agrees with the observation of regular oscillations in the current during the anodization (Fig. 8). Due to this rotating electrical field, the growth of the $\mathrm{TiO}_{2}$ nanocoil follows a helicoidal path with the formation of a structure similar to rolled paper streamers (Fig. 1). The dimensions of this nanocoil depend on the applied voltage which in turn influences the intensity of this electrical field. Therefore a linear relationship is observed between the voltage during anodization and the TNT mean diameter and wall thickness.

This model of growth also indicates that the nanocoil are already crystalline after anodization, in agreement with our observations, even thought they do not give coherent reflections in GAXRD. The annealing at $450{ }^{\circ} \mathrm{C}$ would give a better ordering of this nanostructure with the elimination of defect states which favor recombination and the lowering of the photo-generated current. The crystalline phases detected by GAXRD after these treatments are related to TNT bottom surface and/or to $\mathrm{TiO}_{2}$ particles present on the top of TNT film.

The characteristics of the TNT considerably influence photo-behavior under irradiation with a low power lamp simulating the solar spectrum. Fig. 11B indicates that although various parameters determine the photo-behavior, a main factor is the band gap which in turn depends on the characteristics of the TNT. Increasing the voltage during anodization increases the wall thickness (Fig. 6) and the band gap shifts toward visible region (Fig. 7B) with an improvement of the photo-generated current density (Fig. 11B). Fig. 11A also evidences that the formation of the TNT improves the photo-generated current, because after $20 \mathrm{~s}$ of anodization the titania layer is already formed (see Fig. 8B), but photo-generated current density further increases up to when the TNT array is fully formed. This demonstrates that the nanostructure is an important aspect in determining the photo-behavior.

\section{Conclusions}

The characterization of titania nanostructured thin films prepared by anodization of titanium foils by different techniques (FESEM, GAXRD, UV-vis diffuse reflectance, current-time transients during the anodization process and photo-generation of current by irradiation with a low-power lamp simulating the solar spectrum) evidenced that: (i) ordered arrays of titania helical nanocoils instead of nanotube (hollow columns), as reported in literature, could be produced and (ii) the nanostructure influences the photo-behavior. In particular, the results show that the characteristics of these titania nanostructures (wall thickness, etc.) influence the band gap due to the fact that in nanocoils, and probably also in nanotubes, the shift to higher energies as expected from quantum size confinement in passing from $3 \mathrm{D} \rightarrow 2 \mathrm{D} \rightarrow 1 \mathrm{D}$ is not present. This is related to the specific nanostructure characteristics and is one of the relevant conclusions. As a consequence, the band gap depends on the specific nanostructure characteristics (such as wall thickness) and this determines the response in the photocurrent generation.

The voltage applied during the anodization influences the mean dimension of these titania nanostructures (TNT), their wall thickness and also their degree of packing. A linear relationship between the wall thickness, in the 5-10 nm range, and the band gap is observed. A main factor which determines the photo-behavior is the band gap which in turn depends on the characteristics of the TNT. Increasing the voltage during anodization increases the wall thickness and the band gap shifts toward visible region with an improvement of the photo-generated current density. It is also demonstrated that the formation of these helical nanocoils improves the photo-generated current with respect to the samples after short anodization where only a titania layer is formed. 


\section{Acknowledgements}

This work was realized in the frame of the collaboration with the EU Network of Excellence IDECAT (Integrated Design of Catalytic Nanomaterials for a Sustainable Production), contract NMP3-CT-2005-011730) and of ELCASS (European Laboratory for Catalysis and Surface Science).

\section{References}

[1] H. Yamashita, M. Takeuchi and M. Anpo In: H.S. Nalwa, Editor, Encyclopedia of Nanoscience and Nanotechnology Vol. 10, American Scientific Publishers, Stevenson Ranch, CA, USA (2004), p. 639.

[2] M. Anpo, S. Dohshi, M. Kitano and Y. Hu In: J.L.G. Fierro, Editor, Metal Oxides Vol. 108, CRC Press LLC (2006), p. 595.

[3] A.G. Agrios and P. Pichat, J. Appl. Electrochem. 35 (2005), p. 655.

[4] J.M. Herrmann, Top. Catal. 34 (2005), p. 49.

[5] H. Yamashita, M. Honda, M. Harada, Y. Ichihashi, M. Anpo, T. Hirao, N. Itoh and N. Iwamoto, J. Phys. Chem. B 102 (1998), p. 10707.

[6] R. Asahi, T. Morikawa, T. Ohwaki, K. Aoki and T. Taga, Science 293 (2001), p. 269.

[7] T. Ihara, M. Miyoshi, Y. Iriyama, O. Matsumoto and S. Sugihara, Appl. Catal. B: Environ. 42 (2003), p. 403.

[8] V. Subramanian, E.E. Wolf and P.V. Kamat, JACS 126 (2004), p. 4943.

[9] W. Li and I. Shah, Encyclopedia of Nanoscience and Nanotechnology Vol. 9, American Scientific Publishers, Stevenson Ranch, CA, USA (2004), p. 669.

[10] V. Keller and F. Garin, Catal. Commun. 4 (2003), p. 377.

[11] K.O. Varghese and C.A. Grimes, J. Nanosci. Nanotechnol. 3 (2003), p. 277.

[12] (a) M. Gratzel, Nature 414 (2001), p. 338.

(b) M. Gratzel, J. Photochem. Photobiol. A: Chem. 164 (2004), p. 3.

[13] F. Cao, G. Oskam, G.J. Meyer and P.C. Searson, J. Phys. Chem. 100 (1996), p. 17021.

[14] P.E. de Jongh and D. Vanmaekelbergh, Phys. Rev. Lett. 77 (1996), p. 3427.

[15] F. Gracia, J.P. Holgado and A.R. González-Elipe, Langmuir 20 (2004), p. 1688.

[16] T. Kudo, Y. Nakamura and A. Ruike, Res. Chem. Intermed. 29 (2003), p. 631.|

[17] Y. Lin, G.S. Wu, X.Y. Yuan, T. Xie and L.D. Zhang, J. Phys.: Condens. Matter 15 (2003), p. 2917.

[18] S. Yoo, S.A. Akbar and K.H. Sandhage, Adv. Mater. 16 (2004), p. 260.

[19] D. Gong, C.A. Grimes, O.K. Varghese, W. Hu, R.S. Singh, Z. Chen and E.C. Dickey, J. Mater. Res. 16 (2001), p. 3331.

[20] J.H. Jung, H. Kobayashi, K.J.C. van Bommel, S. Shinkai and T. Shimizu, Chem. Mater. 14 (2002), p. 1445. 
[21] G.K. Mor, O.K. Varghese, M. Paulose, N. Mukherjee and C.A. Grimes, J. Mater. Res. 18 (2003), p. 2588.

[22] M. Adachi, Y. Murata, M. Harada and S. Yoshikawa, Chem. Lett. 8 (2000), p. 942.

[23] S. Uchida, R. Chiba, M. Tomiha, N. Masaki and M. Shirai, Electrochemistry 70 (2002), p. 418.

[24] O.K. Varghese, D. Gong, M. Paulose, K.G. Keat, E.C. Dickey and C.A. Grimes, Adv. Mater. 15 (2003), p. 624.

[25] A. Wahl and J. Augustynski, J. Phys. Chem. B 102 (1998), p. 7820.

[26] (a) T. Kasuga, M. Hiramatsu, A. Hoson, T. Sekino and K. Niihara, Langmuir 12 (1998), p. 3160.

(b) S. Uchida, R. Chiba, M. Tomiha, N. Masaki and M. Shirai, Stud. Surf. Sci. Catal. 146 (2003), p. 791.

[27] P. Hoyer, Langmuir 12 (1996), p. 1411.

[28] M. Adachi, Y. Murata, I. Okada and S. Yoshikawa, J. Electrochem. Soc. 150 (2003), p. G488.

[29] N. Wang, H. Lin, J. Li, X. Yang and B. Chi, Thin Solid Films 496 (2006), p. 649.

[30] D. Li and Y.N. Xia, Nano Lett. 4 (2004), p. 933.

[31] J.M. Macak, H. Tsuchiya and P. Schuki, Angew. Chem. 44 (2005), p. 2100.

[32] J. Zhao, X. Wang, T. Sun and L. Li, Nanotechnology 16 (2005), p. 2450.

[33] M. Paulose, G.K. Mor, O.K. Varghese, K. Shankar and C.A. Grimes, J. Photochem. Photobiol. A: Chem. 178 (2006), p. 8.

[34] G.K. Mor, K. Shankar, O.K. Varghese and C.A. Grimes, J. Mater. Res. 19 (2004), p. 2989.

[35] G.K. Mor, K. Shankar, M. Paulose, O.K. Varghese and C.A. Grimes, Nano Lett. 5 (2005), p. 191.

[36] Y. Ohsaki, N. Masaki, T. Kitamura, T. Wada, T. Okamoto, T. Sekino, K. Niihara and S. Yanagida, PCCP 7 (2005), p. 4157.

[37] G.K. Mor, K. Shankar, M. Paulose, O.K. Varghese and C.A. Grimes, Nano Lett. 6 (2006), p. 215.

[38] R. Beranek, H. Tsuchiya, T. Sugishima, J.M. Macak, L. Taveira, S. Fujimoto, H. Kisch and P. Smuki, Appl. Phys. Lett. 87 (2005), p. 243114.|

[39] K.G. Ong, O.K. Varghese, G.K. Mor and C.A. Grimes, J. Nanosci. Nanotechnol. 5 (2005), p. 1801.

[40] O.K. Varghese, M. Paulose, K. Shankar, G.K. Mor and C.A. Grimes, J. Nanosci. Nanotechnol. 5 (2005), p. 1158.

[41] S. Motojima, T. Suzuki, Y. Noda, A. Hiraga, S. Yang, X. Chen, H. Iwanaga, T. Hashishin and Y. Hishikawa, J. Mater. Sci. 39 (2004), p. 2663.

[42] (a) S. Kobayashi, N. Hamasaki, M. Suzuki, M. Kimura, H. Shirai, K. Hanabusa and K. Kenji, JACS 124 (2002), p. 6550.

(b) S. Motojima, T. Suzuki, Y. Noda, A. Hiraga, H. Iwanaga, T. Hashishin, Y. Hishikawa, S. Yang and X. Chen, Chem. Phys. Lett. 378 (2003), p. 111.

[43] (a) G.K. Mor, M.A. Carvalho, O.K. Varghese, M.V. Pishko and C.A. Grimes, J. Mater. Res. 19 (2004), p. 628.

(b) O.K. Varghese, D.W. Gong, M. Paulose, C.A. Grimes and E.C. Dickey, J. Mater. Res. 18 (2003), p. 156. 
[44] A.K.S. Aqili and A. Maqsood, Appl. Opt. 41 (2002), p. 218.

[45] G. Kortüm, Reflectance Spectroscopy, Springer-Verlag Publishers, Heidelberg, Germany (1969).

[46] H. Seel and R. Brendel, Thin Solid Films 451-452 (2004), p. 608.

[47] W. Wunderlich, L. Miao, M. Tanemura, S. Tanemura, P. Jin, K. Kaneko, A. Terai, N. NabatovaGabin and R. Belkada, Int. J. Nanosci. 3 (2004), p. 439.

[48] H. Sato, K. Ono, T. Sasaki and A. Yamagishi, J. Phys. Chem. B 107 (2003), p. 9824.

[49] G.L. Tian, H.-B. He and J.-D. Shao, Chin. Phys. Lett. 22 (2005), p. 1787.

[50] J.-J. Wu and C.-C. Yu, J. Phys. Chem. B 108 (2004), p. 3377.

[51] P. Tyagi and A.G. Vedeshwar, Bull. Mater. Sci. 24 (2001), p. 297.

[52] V.M. Naik, D. Haddad, R. Naik, J. Benci, G.W. Auner, Materials Research Society Symposium Proceedings, vol. 755, Solid-State Chemistry of Inorganic Materials IV, Materials Research Society, 2002, p. 413.

[53] S. Perathoner, P. Lanzafame, R. Passalacqua, G. Centi, R. Schlögl and D.S. Su, Microporous Mesoporous Mater. 90 (2006), p. 347.

[54] G. Patermarakis, J. Electroanal. Chem. 447 (1998), p. 25.

[55] L. Menon, Synthesis of nanowires using porous alumina. In: S. Bandyopadhyay and H.S. Nalwa, Editors, Quantum Dots and Nanowires, American Scientific Publishers (2003), p. 141 (Chapter 4).

[56] J.W. Diggle, T.C. Downie and C.W. Goulding, Chem. Rev. 69 (1969), p. 365. 